DOI 10.37882/2500-3682.2021.10.07

\title{
ИМПРЕССИНГ КАК ОБЪЕКТ МЕЖДИСЦИПЛИНАРНОГО ЭМПИРИЧЕСКОГО ИССЛЕДОВАНИЯ (ПРОГРАММА И ОСНОВНЫЕ РЕЗУЛЬТАТЫ) ${ }^{1}$
}

\section{IMPRESSING AS AN OBJECT OF INTERDISCIPLINARY EMPIRICAL RESEARCH (PROGRAM AND MAIN RESULTS)}

E. Viktorova

G. Kozina

Summary: In the article one of the phenomena of socialization impressing is considered. The current state of studies on it is described, the main problems are indicated, the prospects for further research are outlined. The experience of using sociological and psychologicalpedagogical methods while carrying interdisciplinary empirical research on impressing is presented. Based on the data obtained, an attempt to describe this phenomenon in a parametric and functional manner is made.

Keywords: socialization, teenager, socio-cultural environment, impact, impression, impressing, hobby, activity.

\section{Введение}

$\mathrm{M}$ алочисленность и разрозненность эмпирических исследований импрессинга имеет под собой объективные основания. Уже В.П. Эфроимсон-советский педагог и генетик, первым заговоривший об импрессинге [14], [13], - указывал на специфические черты этого феномена, которые затрудняют его исследование. Ключевыми среди них являются однократность и индивидуальная избирательность воздействий. Для возникновения впечатления («импрессинг» происходит от англ. «impress» - впечатлять, оставлять след), формирующего устойчивое стремление личности к реализации творческого потенциала в определенных видах деятельности, достаточно однократного воздействия социокультурной среды на личность, если такое воздействие происходит в критические (сензитивные) периоды онтогенеза и в ситуациях эмоциональной уязвимости. Однако совпадение указанных факторов не гарантирует возникновение импрессинга, поскольку эффект зависит
Викторова Елена Викторовна

К.п.н., дочент, Пензенский государственный университет vikele@mail.ru

Козина Галина Юрьевна

К.С.н., доцент, Пензенский государственный университет galina-sura@bk.ru

Аннотация: Рассмотрен один из феноменов социализации - импрессинг. Описано современное состояние его изученности, указаны основные проблемы, намечены перспективы дальнейших исследований. Представлен опыт междисциплинарного эмпирического исследования импрессинга с использованием социологических и психолого-педагогических методов. На основании полученных данных предпринята попытка параметрическифункционального описания данного феномена.

Ключевые слова: социализация, подросток, социокультурное окружение, воздействие, импрессинг, впечатление, увлечение, деятельность. от индивидуальной восприимчивости личности к определенным видам воздействий [14].

Возможно, указанными чертами импрессинга обусловлен тот факт, что в настоящее время среди научных работ, посвященных этому феномену, преобладают теоретические. Это проблемно-ориентированные работы, акцентирующие внимание на недостаточной изученности импрессинга при очевидной актуальности, и раскрывающие его потенциал: социально-психологический (А.Б. Долгин, Е.Е. Мазур, В.Н. Сагатовский) и психологопедагогический (О.В. Лишин, И. Родос, Г.Я. Узилевский). Имеют место частные, узкопредметные исследования, в которых импрессинг упоминается в той или иной связи с отдельными психолого-педагогическими феноменами (И.Б. Будик, С.А. Гильманов, Л.С. Грибцова). Опорой же для исследователя, чей научный интерес привлек импрессинг, выступают прежде всего труды В.П. Эфроимсона, в которых природа и функциональная специфика импрессинга описывается на основе обобщений биогра-

1 Исследование выполнено при финансовой поддержке РФФИ в рамках научного проекта № 19-29-14014 «Информационное воздействие на личность в условиях цифровизации культуры и образования как импрессинг: риски и потенциал» (Тһе reported study was funded by RFBR, project number 19-29-14014). 
фического материала - фактов импрессинга в жизни выдающихся деятелей различных сфер: науки, искусства, политики и т.д. [13]. Безусловный интерес представляют также работы М. Амусьи и М. Перельмана, в которых результаты биографического анализа экстраполированы на общественный уровень и показано, как импрессинг влияет на ход исторических событий [8]. Отправной точкой в понимании непосредственно психолого-физиологического механизма импрессинга выступают работы, в которых прямо или косвенно речь идет о феномене, близком к импрессингу, - об импринтинге [1], [4], [5], [12].

Анализ междисциплинарного массива работ, могущих служить базой для исследования импрессинга, позволяет говорить о недостаточности научных сведений о нем как о сложном биосоциокультурном феномене, о потребности в приращении фундаментальных знаний, которое возможно только при проведении эмпирических исследований, несмотря на неоднозначность импрессинга как предмета изучения.

\section{Программа исследования}

Первое проведенное нами эмпирическое исследование импрессинга, которое можно назвать пилотажным, состоялось с участием более 400 респондентов в возрасте 18-65 лет и позволило предпринять попытку параметрически-функционального описания импрессинга. На основе полученных первичных данных, их анализа и последующего обобщения осуществлено предварительное типологизирование импрессинга по нескольким критериям [3]. Кроме того, был сделан вывод об одном из сензитивных (критических) для возникновения импрессинга периодов как о самом благоприятном для проведения основного исследования [2]. Таким периодом оказался подростково-юношеский возраст. Именно из этой возрастной группы была сформирована выборка основного исследования.

Программа основного исследования выстроена с учетом опыта пилотажного исследования: оптимизирован выбор методов, скорректированы вопросы анкеты в соответствии с поставленными задачами, адаптированы к возрастным особенностям респондентов.

Целью основного исследования стало выявление сущностных характеристик импрессинга и специфики его функционирования.

Задачи:

1. Уточнить сензитивные для возникновения импрессинга возрастные периоды развития личности;

2. Определить роль ближайшего социального окружения в возникновении импрессинга;

3. Выявить факторы, способствующие возникнове- нию импрессинга и проявлению его последствий;

4. Определить место и роль интернета в возникновении импрессингов современных детей.

Рабочие гипотезы исследования:

1. Наиболее благоприятным для возникновения импрессинга является младший подростковый возраст;

2. Большая часть импрессингов происходит в семейной среде;

3. Для возникновения и закрепления результатов импрессинга необходима поддержка референтных лиц;

4. Импрессинги современных детей чаще происходят в цифровой среде, а не в реальной действительности.

В основном исследовании приняли участие 516 респондентов в возрасте 13-19 лет. Расчет выборочной совокупности произведен следующим образом. Согласно данным Территориального органа Федеральной службы государственной статистики по Пензенской области [11], объем генеральной совокупности на начало 2019 г. составил 30360 чел. При величине допустимой ошибки равной $5 \%(\Delta=0,05)$ и доверительной вероятности равной 95\% (P=0,954) объем репрезентативной выборочной совокупности с запасом будет составлять не менее 400 случайно отобранных единиц [7]. Было принято взять объем выборочной совокупности равной 550 чел. Такое число обусловлено, с одной стороны, зависимостью объема выборки от объема генеральной совокупности и величины допустимой ошибки, с другой стороны, учетом квотирования выборки на возрастные группы, контроля поля, а также контроля качества и возможной выбраковки анкет. Для опроса указанной возрастной категории нами была использована поэтапная выборка, в которой сначала случайным образом были определены кластеры, затем по квотному признаку отобраны учащиеся. Таким образом, в результате проверок ошибок поля, контроля качества и выбраковки анкет анализу было подвержено 516 анкет без нарушения квотной доли.

Исследование учитывает сложную биосоциокультурную природу импрессинга и является междисциплинарным: оно проведено с использованием социологических и психолого-педагогических методов. Применены анкетный опрос, фокус-группа (проведены четыре фокус-группы по 10-12 человек), выборочное глубинное интервью, методика «Незавершенное предложение», тестирование («Шкала оценки потребности в достижении», «Исследование волевой саморегуляции» (А.В. Зверьков, Е.В. Эйдман), «Диагностика нравственной самооценки» (Н.И. Дереклеева)). Анкетный опрос нацелен на получение данных о возрастных особенностях импрессинга, о среде, факторах и предикторах его возникновения, о роли референтных лиц, о направленности последствий 
импрессинга. Другие методы были призваны углубить данные анкетирования (фокус-группа, методика «Незавершенное предложение»), уточнить их и выявить/не выявить корреляции между ответами (тесты).

Исследование позволило уже «в первом приближении» получить довольно обширный массив данных об импрессинге, анализ которых в различных аспектах (в соответствии с выдвинутыми задачами) достоин отдельных научных статей. В данной статье представим основные результаты проведенного исследования.

\section{Основные результаты}

Среди сензитивных периодов для возникновения сильных значимых впечатлений выделяется подростковый возраст (первая гипотеза подтверждена). 34,9\% опрошенных (180 чел.) считают, что пережили импрессинг в возрасте 10-12 лет (младший подростковый). На втором месте по частоте возникновения находится младший школьный возраст (на него указали 24\% (124 чел.) и старший подростковый (23,3\% (120 чел.). Обратим внимание, что, если для импринтинга, с которым нередко отождествляют импрессинг, критическим является период раннего детства, то в случае с импрессингом этот возраст не является настолько значимым. Только 5,8\% (30 чел.) опрошенных указали на этот возраст. Эти данные соответствуют данным, полученным в ходе пилотажного исследования, и подтверждают мнение В.П. Эфроимсона о том, что не следует проводить прямые аналогии между импринтингом и импрессингом: если механизм формирования следа (запечатление/впечатление) действительно схож, то функциональные характеристики, к которым относится и критический возраст, у них значительно различаются. Не случайно результатом импринтинга человека является стойкое следование запечатленной информации в ситуациях, схожих с пережитой, а результатом импрессинга - настойчивое устремление к определенному виду творческой деятельности.

Здесь следует отметить, что пережитые впечатления импрессинговыми, или повлекшими за собой какое-то увлечение, посчитали сами респонденты. Однако для того, чтобы характеризовать увлечение как последствие импрессинга, необходимо понять, насколько стремление к нему является сильным. Проведенные фокус-группы свидетельствуют о том, что в описании своих увлечений подростки чаще всего используют слово «нравится»: нравится танцевать, рисовать, играть в футбол и т.п. Однако «нравится» еще не означает свойственной последствиям импрессинга почти всепоглощающей увлеченности любимым делом. 89,9\% (464 чел.) опрошенных ребят в подростковом возрасте уже имеют увлечение. Но сопоставление ответов на соответствующие вопросы анкеты показало, что из всех увлеченных ребят высокую устремленность к своему делу проявляют 33,2\% (154 чел.). Соотнесение данных анкетирования с данными теста-опросника «Исследование волевой саморегуляции», свидетельствует о том, что 55,4\% (286 чел.) способны проявлять настойчивость высокого уровня. А соотнесение данных анкетирования с данными «Шкалы оценки потребности в достижении» показывает, что у 52,7\% (271 чел.) средний уровень мотивированности в своей деятельности. К проявлению же высокой мотивации В своей деятельности способны только 2,3\% (12 чел.). Следовательно, половина имеющих увлечение ребят способны проявлять черты, необходимые для серьезной увлеченности своим делом, но проявляют их только треть. Данные позволяют предположить, что увлечение именно этой части подростков может являть собой последствие импрессинга. (Полученные результаты требуют ведения дальнейших подсчетов, исходя из выборки 154 человека - респонденты, чьи увлечения можно позиционировать как результат импрессинга.)

В результате исследования уточнена типологическая характеристика импрессинга. Анализ данных о социокультурной среде возникновения импрессингов позволяет условно представить их как связанные с лицами из ближайшего (неформального) окружения, связанные с формальными агентами социализации, непосредственно не связанные с ними, т.е. те, источниками которых стали природа, сновидения, произведения искусства, памятники культуры, культовые объекты и др.

Исследование позволило выявить и содержательную специфику импрессингов в соотнесении с возрастными периодами. Так, для подросткового периода характерны импрессинги, возникающие в процессе общения с ровесниками, особенно противоположного пола, а также в процессе восприятия произведений искусства, во время ознакомления с памятниками культуры и т.п.

Однако особое место в любом из критических периодов занимают импрессинги, полученные в семейной среде (вторая гипотеза подтверждена частично: роль семейной среды стабильно высока, но непосредственная роль родителей меняется в зависимости от возраста). Материалы интервью и методики «Незаконченное предложение» содержат описание сильных и значимых впечатлений, полученных именно в семье. В зависимости от возраста от 13,6\% до $18,8 \%$ отметили, что импрессинговым для них оказался непосредственно разговор с родителями. При этом роль родителей в прямом импрессинговом воздействии заметно снижается в процессе взросления детей: это чаще случается в младшем подростковом, чем, например, в старшем подростковом возрасте. Разговор с другими членами семьи стал источником импрессинга для 1,2\% ребят (2 чел.). Наблюдение за чем-то, что вызвало импрессинг, в деятельности, поведении или словах близких родственников, в том числе родителей, стало источником импрессинга для 3,3\% 
ребят (5 чел.). И, наконец, значительно число импрессингов, хотя и не связанных с общением с близкими родственниками, но произошедших именно дома (дома за чтением, дома за компьютером и т.п.) - 38,3\% (59 чел.).

Значение семейной среды подтверждают и данные о том, с кем делятся подростки своими переживаниями об увлечениях. Здесь данные также разнятся в зависимости от возраста: если среди 11-летних 52,6\% делятся с мамой и 46,7\% - с папой, то в возрасте 14 лет эти показатели снижаются до 24\% и 19,4\% соответственно (здесь, как уже отмечалось резко возрастает роль ровесников-друзей - с ними делятся своими переживаниями 50\% старших подростков).

В числе ключевых факторов, способствующих возникновению импрессинга, кроме сензитивного (критического) периода развития, необходимо отметить ситуацию эмоциональной уязвимости. Мы не склонны рассматривать эмоциональные свойства личности как предикторы возникновения импрессинга. Здесь мы опираемся на исследования психофизиологического механизма запечатлевания [4], [5],[6], согласно которым внешнее воздействие может оставить след в памяти у любого человека, но в ситуациях, которые способны вызвать его эмоциональную (импринтную) уязвимость.

Соотношение данных анкетирования, методики «Незавершенное предложение» и глубинного интервью позволяют сделать основной вывод - содержательная специфика ситуации эмоциональной уязвимости является индивидуальной, зависит от особенностей первичной социализации отдельно взятого подростка. Однако обнаруживает себя и общая предпосылка ситуаций эмоциональной уязвимости: они во многом обусловлены возрастными социально-психологическими компонентами сензитивного периода. Имеют значение в данном случае ведущий в конкретном возрасте вид деятельности (игра, обучение, общение), референтные для возраста лица ближайшего окружения (родители, друзья). Безусловно, есть взаимосвязь с психическими новообразованиями (например, развитие самосознания подростка приводит к тому, что он эмоционально уязвим в ситуациях, когда подвергается оценке его Я). Это находит подтверждение в указанных выше данных о ситуациях возникновения импрессинга, среди которых преобладают ситуации общения с родителями, ровесниками, друзьями.

В.П. Эфроимсон, опираясь на биографический анализ, высказал предположение о том, что на импрессинговый эффект (устремленность к деятельности) может влиять фактор препятствия [13]. Содержание препятствия как такого в данном случае носит преимущественно индивидуальный характер. Однако, учитывая значительную роль ближайшего социокультурного окружения в возникновении импрессинга, в качестве препятствующих/способствующих факторов можно рассматривать отношение референтных лиц к увлечению подростка (поддержка, запрет и т.п.). 78\% (120 чел.) подростков отмечают, что чужое мнение об их увлечении для них не имеет значения. Однако вопросы о конкретной - отрицательной или положительной - оценке их деятельности и ее результатов продемонстрировали иные ответы. Уже лишь треть опрошенных отмечает, что не обратит внимания на негативную оценку (хотя данные фокус-группы свидетельствуют о том, что такой процент должен быть еще ниже), 19,4\% (30 чел.) признаются, что испытают злость и это мотивирует их к более активной и качественной деятельности. 10,4\% (16 чел.) испытают злость и «выплеснут» свои эмоции на критикующего (данные фокус-группы заставляют думать, что этот процент должен быть выше). И еще 10,4\% (16 чел.) будут переживать по поводу негативной оценки, но удержат эмоции в себе. Ответы на вопрос о похвале, поддержке в увлечении также не позволяет уверенно говорить о равнодушии подростков к чужому мнению. 37\% (57 чел.) опрошенных уверены в том, что им не важна поддержка в их увлечении. 27,2\% (42 чел.) подростков такая поддержка нужна независимо от лица, ее проявляющего. И еще $35,7 \%$ (55 чел.) она нужна в проявлении конкретных лиц: 12,3 \% - профессионала в этом деле, 9,1\% - мамы, 4,5\% - друга, 4,5\% - любого, увлеченного тем же, 3,8\% - папы, 1,2\% - учителя. Отметим, что ответы на указанные вопросы коррелируют с данными, полученными тестом-опросником «Исследование саморегуляции» по шкале «Самообладание», но не коррелируют с данными, полученными по «Шкале оценки потребности в достижении». Принято считать, что поддержка близкими людьми своих подростков в их деятельности принципиально важна, однако, видимо, это имеет большое значение для качества межличностных отношений как таковых, но для устремления подростков к любимой деятельности, вызванной к жизни импрессингом, такого значения не имеет.

Исходя из сказанного, можно лишь частично подтвердить третью гипотезу. Поддержка референтных лиц имеет значение для подростков, переживших импрессинг, но о ее прямом влиянии на устремленность к деятельности, вызванной импрессингом, говорить нельзя. Анализ биографического материала, представленного в работах В.П. Эфроимсона, косвенно подтверждает эту мысль: творческая личность испытывает необъяснимую тягу к своей деятельности и занимается ею и «благодаря», и «вопреки» [14], [13]. Не случайно, лишь от 12,9\% до $20,1 \%$ подростков в зависимости от возрастной категории уверены, что от своего увлечения не откажутся, потому что не мыслят без него свою жизнь.

И, наконец, представление основных результатов исследования невозможно без упоминания места и роли интернета в возникновении импрессинга и проявлении 
его последствий. 24\% (37 чел.) подростков указали на то, что пережили импрессинг в социальных сетях, еще 13,6\% (21 чел.) - также в интернет, но на других сайтах. Таким образом, четвертая гипотеза о том, что импрессинги современных детей чаще происходят в цифровой среде, а не в реальной действительности, опровергнута. Однако общий процент подростковых сильных впечатлений, полученных в интернет и приведших к появлению увлечения, довольно высок. Кроме того, исследование показало значительную роль интернета не только в возникновении импрессинга. 13\% (20 чел.) ребят делятся впечатлениями от своего увлечения в интернет-сообществах, 12,3\% (19 чел.) ищут и находят в них поддержку. От $5,2 \%$ до $18,1 \%$ в зависимости от возраста имеют увлечение, непосредственно связанное с интернетом. И 44,2\% (68 чел.) используют интернет для получения информации о своем увлечении.

\section{ЗакАючение}

В случае с таким объектом исследования, как импрессинг, который возникает уже при однократном воздействии среды на личность и механизм которого включает наследственный компонент, невозможно опереться на воспроизводимость результатов. Однако, по нашему мнению, это не должно препятствовать его дальнейше- му исследованию. Учет основных факторов, влияющих на возникновение сильного личностно значимого впечатления (критический период онтогенеза, ситуации эмоциональной уязвимости) должен и может стать опорой для проведения репрезентативных исследований. Это особенно важно, когда речь идет о феномене, последствия которого могут иметь не только личностное, но общественное, социокультурное значение. И акцентированные нами специфические черты импрессинга свидетельствуют об особой «тонкости», деликатности феномена в индивидуальной жизни. Однократность импрессингового воздействия требует более внимательного и чуткого отношения к личности подростка, а наследственная «избирательность» воздействий предполагает более доверительное отношение значимых взрослых к выбору подростком интересующих его занятий, что особенно актуально и, на первый взгляд, рискованно в условиях цифровизации детства [9], [10].

Дальнейшие перспективы мы видим в исследовании факторов/предикторов импрессинга (общевозрастных и индивидуальных), среди которых особое внимание следует уделить тем, которые поддаются учету и корректировке, - социокультурным и социально-психологическим.

\section{ЛИТЕРАТУРА}

1. Боулби Д. Привязанность [Электронный ресурс]. М.: Гардарики, 2003. Режим доступа: http://nkozlov.ru/library/psychology/d4590/ (дата обращения 11.07.2021).

2. Викторова Е.В. Возрастные характеристики импрессинга (опыт эмпирического исследования) // The Unity of Science: International scientific periodical journal. - 2016. - № 3-1. - C. 65-68.

3. Викторова Е.В. Социокультурное многообразие импрессинга: опыт типологизации // Международный научно-исследовательский журнал. - 2021. - № 8 (110). - Часть 3. - С. 192-196.

4. Гроф С. Психология будущего: уроки современных исследований сознания. - М.: АСТ, 2003. - 458 с.

5. Лири, Т., Стюарт М. Деструктивные психотехники. Технологии изменения сознания в деструктивных культах. - СПб: Экслибрис. $2002 .-224$ с.

6. Майнарди Д. Собака и лисица. Правдивый рассказ о свободном путешествии по царству этологии. - М.: Мир, 1980. - 151 с.

7. Паниотто В.И. Качество социологической информации (методы оценки и процедуры обеспечения). - Киев: Наукова думка, 1986. - С. 80-82.

8. Перельман М., Амусья М.. Особенности формирования менталитета человека [Электронный ресурс]. Режим доступа: http://world.lib.ru/ (дата обращения 19.07.2021).

9. Писаренко И.А., Заиченко Л.И. Родители как субъекты влияния на развитие цифровых навыков детей // Интеракция. Интервью. Интерпретация. - 2021. - T. 13. - № 2. - C. 54-80.

10. Солдатова Г.У., Рассказова Е.И. Неосведомленность родителей о столкновении подростков с рисками в интернете: содержание и психологические факторы // Психологический журнал. - 2019. - Т. 40. - № 1. - С. 71-83.

11. Территориальный орган Федеральной службы государственной статистики по Пензенской области. [0фициальный сайт]. Режим доступа: https://pnz.gks. ru/ (дата обращения: 20.02.2021).

12. Хорн Г. Память, импринтинг и м0зг. - М.: Мир, 1988. - 154 с.

13. Эфроимсон В.П. Генетика гениальности. - М.: Время знаний, 2010. - 375 с.

14. Эфроимсон В.П. Педагогическая генетика // Биология. - 2000. - № 30. - С.5-11; №31. - С.5-11; №32. - С.5-11. 